\title{
Progeny of Selfed Plants from Tomato Breeding Line 'NC1 Grape' Overexpressing Mannitol Dehydrogenase (MTD) Have Increased Resistance to the Early Blight Fungus, Alternaria solani
}

\begin{abstract}
Takshay K. Patel, Sergei F. Krasnyanski, and George C. Allen, Department of Horticultural Science, North Carolina State University, Raleigh 27695-7609 USA; Frank J. Louws, Department of Plant Pathology, North Carolina State University, Raleigh 27695-7616 USA; and Dilip R. Panthee and John D. Williamson, Department of Horticultural Science, North Carolina State University, Raleigh 27695-7609 USA
\end{abstract}

Accepted for publication 7 August 2015. Published 14 August 2015.

\section{ABSTRACT}

Patel, T. K., Krasnyanski, S. F., Allen, G. C., Louws, F. J., Panthee, D. R., and Williamson, J. D. 2015. Progeny of selfed plants from tomato breeding line 'NC1 Grape' overexpressing mannitol dehydrogenase (MTD) have increased resistance to the early blight fungus, Alternaria solani. Plant Health Progress doi:10.1094/PHP-RS-15-0022.

Reactive oxygen species (ROS) made by plants in response to pathogen infection not only initiate local and systemic defenses, they are also antimicrobial. A number of fungi are hypothesized to secrete the antioxidant mannitol to protect against this antimicrobial ROS during infection. This hypothesis is supported by reports that overexpression of the mannitol catabolic enzyme mannitol dehydrogenase (MTD) in plants increases resistance to mannitol-secreting pathogens like Botrytis cinerea and Alternaria alternata. To extend this hypothesis and test the general utility of this approach, we overexpressed celery MTD in a tomato breeding line (NC1 Grape) currently used in our program. Although we reported earlier that MTD overexpression provides resistance to Botrytis gray mold in a greenhouse tomato, this is the first report of overexpression in an elite breeding variety providing heritable, whole-plant resistance to $A$. solani (tomato early blight). In this study, progeny from a high-MTD-expressing line had infection rates $<65 \%$ those of nontransformed plants, and transformants outgrew infection by 7 days post-inoculation. Finally, our results suggest that screening for higher innate MTD expression in plants, rather than screening solely for the presence of the $M t d$ gene, might be a more effective way to identify parental lines for use in conventional breeding of early blight resistance.

\section{INTRODUCTION}

Reactive oxygen species (ROS) produced by both fungal and plant NADPH oxidases (Nox's) are important components of the plant-pathogen interaction. Characterization of Nox in Alternaria alternata (Morita et al. 2013; Yang and Chung 2012) showed that AaNox expression is critical for virulence and necrotic lesion formation. Plants also produce ROS as a key component of multiple defense responses against these same pathogens (Levine et al. 1994). As a result, necrotrophic pathogens like Alternaria spp. require very effective mechanisms to survive the antimicrobial effects of ROS produced both by themselves and the host plant (Dulermo et al. 2010; Vélëz et al. 2008). Although induction of global stress responses via expression of transcription factors such as YAP1 (Lin et al. 2009; Yang et al. 2009) are reported to help Alternaria spp. survive oxidative stress, few single fungal compounds have been shown to provide effective ROS resistance. One of these few, however, is the host-induced, antioxidant/ compatible solute mannitol (Chaturvedi et al. 1997; Smirnoff and Cumbes 1989), which is secreted by fungal pathogens during plant infection (Jennings et al. 1998). In fact, A. alternata mutants defective in mannitol production and secretion have been shown to be less virulent than wildtype strains on tobacco (Vélëz et al. 2008). Consistent with this proposed role for extracellular fungal mannitol, tobacco plants expressing a mannitol transporter gene (AgMaT2) (Juchaux-Cachau et al. 2007) were found to be more resistant to Alternaria longipes. This is presumably due to the plant's newly acquired ability to remove fungal mannitol from the site of infection by cellular uptake.

On the other side of this interaction, all plants assessed to date make and/or secrete the mannitol catabolic enzyme mannitol dehydrogenase (MTD) in response to pathogen infection (Blackburn et al. 2010; Cheng et al. 2009; Jennings et al. 1998; Jennings et al. 2002; Williamson et al. 1995), presumably to convert mannitol to the non-quenching sugar mannose. If this hypothesis is so, then increased levels of MTD would be expected to provide increased resistance to mannitol-secreting fungal pathogens. This is, in fact, consistent with our previous demonstration that transgenic tobacco overexpressing MTD was more resistant to A. alternata (Jennings et al. 2002). More recently, we showed that the necrotrophic pathogen Botrytis cinerea also secretes mannitol, and that overexpression of MTD in geranium (Williamson et al. 2013) and the greenhouse tomato 'Moneymaker' (Patel et al. 2015) confers significant resistance to $B$. cinerea. Here, we assessed the effect of MTD overexpression in Solanum lycopersicum 'NC1 Grape', an elite tomato breeding line (Gardner and Panthee 2010), on resistance to the early blight fungus, Alternaria solani.

Corresponding author: John D. Williamson. Email: john_williamson@ncsu.edu 


\section{OVEREXPRESSION OF MTD IN THE TOMATO BREEDING}

\section{LINE 'NC1 GRAPE'}

Solanum lycopersicum 'NC1 Grape' was transformed using Agrobacterium tumefaciens strain GV3101 containing the plasmid pTN214N8 (Williamson et al. 2013) as described in Patel et al. (2015). Resulting kanamycin-resistant regenerants were screened for the presence of the 35S-Mtd transgene by PCR, using forward primers GAACTCGCCGTAAAGACTGG and AAACCTCCTCGGATTCCATT (35S-FWD1 and 35S-FWD2, respectively) and reverse primers GAACTCGCCGTAAAGAC TGG and AAACCTCCTCGGATTCCATT (nosT-REV1 and nosT-REV2, respectively). A total of fifteen kanamycin-resistant regenerants were screened, of which nine plants had the Mtd transgene.

To assess expression of these transgenes, proteins were first extracted from $0.2 \mathrm{gm}$ tissue from young, fully expanded leaves (5 to $6 \mathrm{~cm}$ ) of primary transformants ( $\mathrm{T}_{0}$ 's) as well as nontransformed (wildtype, WT) and vector-transformed controls (kanamycin resistant but lacking the $M t d$ transgene) by grinding directly in Bio-Rad (Richmond, CA) SDS sample buffer (1:2 $\mathrm{w} / \mathrm{v})$. Protein concentrations were determined by the method of Bradford (1976). Proteins $(20 \mu \mathrm{g})$ were then separated by SDS-PAGE (Laemmli 1970), blotted onto nitrocellulose, and probed with an anti-MTD serum (1:2,000) (Stoop et al. 1995). Serum cross-reacting proteins were visualized using an alkaline phosphatase (AP)-linked secondary antibody $(1: 2,400)$ (Promega Corp., Madison, WI). Of the nine transformants displaying a wildtype phenotype (i.e., displaying no transformation/tissue culture-induced developmental abnormalities), only one expressed high levels of MTD protein (NCG12, Fig. 1); three expressed levels intermediate between wildtype and NCG12 (e.g., NCG19, Fig. 1); and the remaining five expressed MTD at approximately the same level as wildtype (data not shown).

\section{TESTING RESISTANCE TO EARLY BLIGHT}

Spores of the fungal pathogen Alternaria solani (a field strain isolated from tomato by Dr. Tika Adhikari, Department of Plant Pathology, NC State University, and subsequently identified using species-specific primers, microsatellite analysis, and pathogenicity assays) were stored at $-20^{\circ} \mathrm{C}$ in $15 \%$ glycerol. To initiate sporulation, $50 \mu \mathrm{l}$ of this spore stock was transferred onto potato dextrose agar (PDA) (Benton, Dickinson Co., Sparks, MD) pH 5 and maintained at $25^{\circ} \mathrm{C}$ with an $8 / 16$-h light/dark photoperiod in a controlled humidity chamber (Percival Scientific, Inc., IA). Significant sporulation was observed 14 to 18 days after plating. Sporulating cultures were overlaid with $10 \mathrm{ml}$ sterile $0.01 \%$ aqueous Tween 80 and the resulting spore suspensions collected. Spore suspensions were filtered through two layers of sterile cheesecloth, quantified using a hemocytometer and diluted to desired concentrations.

Seed from selfed, primary transformants $\left(\mathrm{T}_{0}\right.$ 's) were germinated on medium containing $1 / 2 \mathrm{MS}$ salts, kanamycin (100 $\mathrm{mg} / \mathrm{liter})$, and agar (6 g/liter) at $\mathrm{pH} 5.6$ to produce secondgeneration tomato seedlings and plants $\left(\mathrm{T}_{1}\right.$ 's). Seedlings from one high (plant 12) and one lower (plant 19) MTD expresser, as well as from a nontransformed control plant, were selected for analysis. This population was still segregating for the Mtd transgene, so only plants/seedlings with the Mtd transgene grew on kanamycin selection. Seedlings (6 to $8 \mathrm{~cm}$ in height) were transferred to small plastic pots with soil, and covered with clear plastic covers at $25^{\circ} \mathrm{C}$ for one week to acclimate. After acclimation, seedlings ( 12 to $15 \mathrm{~cm}$ in height) were arranged in a random complete block design with 8 to 12 plants per experimental unit for 8 replications and inoculated by spraying with $A$. solani spores
A)
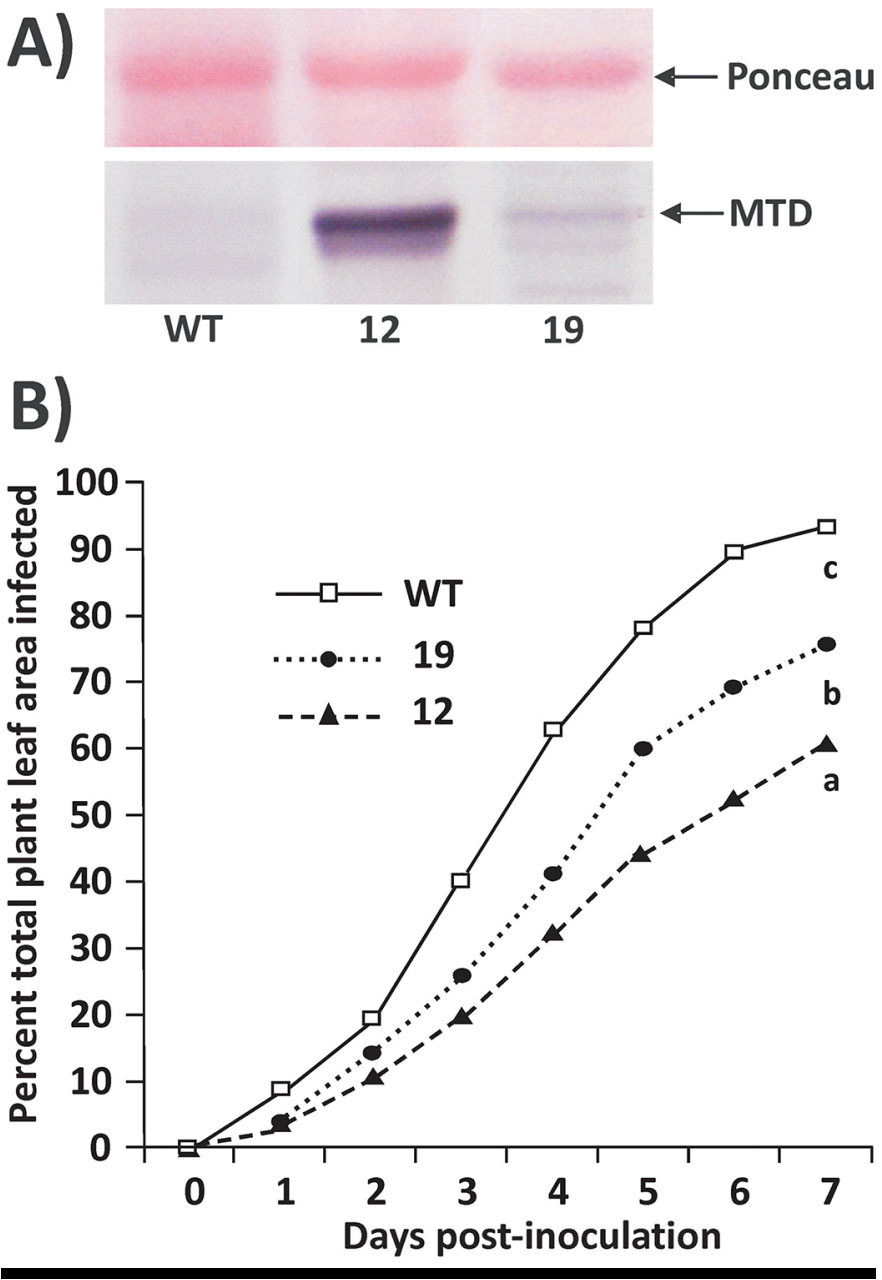

\section{FIGURE 1}

Resistance to Alternaria solani in progeny of MTD over-expressing breeding lines of Solanum lycopersicum 'NC1 Grape'. MTD protein from $T_{0}$ plants of one high (plant 12) and one intermediate (plant 19) MTD-expressing lines, and nontransformed (WT) plants were visually assessed by protein blot analyses. Segregating seedling populations from MTD transformed lines NCG12, NCG19, as well as WT controls were assessed for resistance. Seedlings were arranged, inoculated and scored for resistance as indicated above. (A) Blot analysis of MTD protein in $M t d$-transformed and nontransformed (WT) controls. The Ponceau-stained blot is included to document protein loading and transfer. (B) Disease development was scored over a period of 7 days as a relative percentage of the total leaf tissue area, with total plant leaf area being $100 \%$. Means from 8 to 12 seedlings for each line are shown. Differences in resistance among the three lines on day 7 were compared by ANOVA. Means with different letters are significantly different from each other on day 7 at $P<0.05$.

$\left(10^{6} \mathrm{spores} / \mathrm{ml}\right)$. The spore concentration used was determined in preliminary experiments by inoculating wildtype seedlings with a range of spore concentrations $\left(10^{4}\right.$ to $10^{7}$ spores $\left./ \mathrm{ml}\right)$. The lowest spore concentration producing complete infection on WT plants was used for inoculations (in this case, $1.8 \times 10^{6}$ spores $/ \mathrm{ml}$ ). Symptom development was assessed as the percentage of infected leaf tissue area, with the entire seedling leaf area being $100 \%$. Infected area was recorded every $24 \mathrm{~h}$ through 7 days postinoculation, or until seedlings began to die. Differences in resistance were compared using Repeated Measure Analysis and Analysis Of Variance (ANOVA) in Statistical Analysis Software (SAS v. 9.3, SAS Institute Inc., Cary, NC). An average of 96 
seedlings from each of two selfed, independent MTD overexpressing lines (plants 12 and 19), as well as non-transformed (WT) seedling controls, were assessed for A. solani resistance.

Progeny from the high MTD-expressing line NCG12 showed significantly less infection than seedlings from the other groups $(P<0.05)$ (Fig. 1), with infection rates less than $65 \%$ and new growth appearing on day 7 post-inoculation. Seedlings from the intermediate MTD-expressing line NCG19 had intermediate resistance, with infection rates less than $75 \%$, while the WT controls had a terminal disease index of greater than $95 \%$ by the end of day 7 .

\section{CONCLUSIONS AND POTENTIAL APPLICATIONS}

In this study, plants expressing high levels of MTD suppressed early blight symptoms caused by the necrotrophic pathogen $A$. solani. These results are consistent with the hypothesis that mannitol secretion by necrotrophic pathogens like $A$. solani is important for pathogen survival, presumably by protecting the pathogen from the effects of ROS during infection. We further hypothesize that the timely/immediate removal of pathogenproduced mannitol by the plant-produced MTD exposes fungal structures to the antimicrobial effects of ROS. While $M t d$ homologs are present in tomato (Lauter 1996), the amount of MTD expressed naturally is typically much lower than in MTD overexpressing plants (Fig. 1A, WT). Further, salicylic acid, INA (2,6-dichloroisonicotinic acid), and fungal elicitors induce MTD expression in other non-mannitol plants (Jennings et al. 1998; Kiedrowski et al. 1992; Williamson et al. 1995) although the induced amounts reported are still lower than in MTD overexpressing plants. If this were also true for MTD induction in tomato, levels might be too low to provide resistance to mannitolsecreting pathogens. The decrease in susceptibility to $A$. solani in seedlings expressing high constitutive amounts of MTD (NCG12) supports the hypothesis that the interaction of mannitol and MTD forms an important and dynamic interface during infection by mannitol-secreting fungal pathogens. Although we have previously reported that overexpression of an $M t d$ transgene provides resistance to Botrytis gray mold in a greenhouse tomato, this is the first report of MTD overexpression in an elite breeding variety (NC1 Grape) providing seed-transmissible, whole-plant resistance to $A$. solani, the causal agent of tomato early blight. In addition, although $M t d$ gene copy number was not determined for the primary transformants $\left(\mathrm{T}_{0}\right.$ 's), it should be noted that populations assessed here are segregating, and thus presumably consist of a mix of $1 \times$ and $2 \times$ the base $M t d$ gene copy of those primary transformants. Finally, these results suggest that selection of breeding lines with high naturally occurring MTD expression could provide a useful approach for conventional breeding of resistance against early blight.

\section{ACKNOWLEDGMENTS}

This work was funded by a Specialty Crops Block Grant from NCDA/USDA to authors Williamson, Panthee, Allen, and Krasnyanski. We thank Dr. Wei-wen Guo and Ragy Ibrahem for technical assistance.

\section{LITERATURE CITED}

Blackburn, R. K., Cheng, F-y., Williamson, J. D., and Goshe, M. B. 2010. Data-independent liquid chromatography/mass spectrometry (LC/MS ${ }^{\mathrm{E}}$ ) detection and quantification of the secreted Apium graveolens pathogen defense protein mannitol dehydrogenase. Rapid Commun. Mass Spectrom. 24:1009-1016

Bradford, M. M. 1976. A rapid and sensitive method for the quantitation of microgram quantities of protein utilizing the principle of protein-dye binding. Anal. Biochem. 72:248-252.
Chaturvedi, V., Bartiss, A., and Wong, B. 1997. Expression of bacterial $m t l D$ in Saccharomyces cerevisiae results in mannitol synthesis and protects a glycerol-defective mutant from high-salt and oxidative stress. J. Bacteriol. 179:157-162.

Cheng, F-y., Zamski, E., Guo, W-w., Pharr, D. M., and Williamson, J. D. 2009. Salicylic acid stimulates secretion of the normally symplastic enzyme mannitol dehydrogenase (MTD): A possible defense against mannitol secreting fungal pathogens. Planta 230:1093-1103.

Dulermo, T., Rascle, C., Billon-Grand, G., Gout E., Bligny, R., and Cotton, P. 2010. Novel insights into mannitol metabolism in the fungal plant pathogen Botrytis cinerea. Biochem. J. 427:323-332.

Gardner, R. G., and Panthee, D. R. 2010. Grape tomato breeding lines: NC 1 Grape, NC 2 Grape, and NC 3 Grape. HortScience 45:1887-1888.

Jennings, D. B., Ehrenshaft, M., Pharr, D. M., and Williamson, J. D. 1998. Roles for mannitol and mannitol dehydrogenase in active oxygen-mediated plant defense. Proc. Natl. Acad. Sci. U.S.A. 95:15129-15133.

Jennings, D. B., Daub, M., Pharr, D. M., and Williamson, J. D. 2002. Constitutive expression of a celery mannitol dehydrogenase in tobacco enhances resistance to the mannitol-secreting fungal pathogen Alternaria alternata. Plant J. 32:41-49.

Juchaux-Cachau, M., Landouar-Arsivaud, L., Pichaut, J. P., Campion, C., Porcheron, B., Jeauffre, J., Noiraud-Romy, N., Simoneau, P., Maurousset, L., and Lemoine, R. 2007. Characterization of AgMaT2, a plasma membrane mannitol transporter from celery, expressed in phloem cells, including phloem parenchyma cells. Plant Physiol. 145:62-74.

Kiedrowski, S., Kawalleck, P., Hahlbrock, K., Somssich, I., and Dangl, J. L. 1992. Rapid activation of a novel plant defense gene is strictly dependent on the Arabidopsis RPM1 disease resistance locus. EMBO J. 11:4677-4684.

Laemmli, U. K. 1970. Cleavage of structural proteins during the assembly of the head of bacteriophage T4. Nature 227:680-685.

Lauter, F-R. 1996. Root-specific expression of the LeRse-1 gene in tomato is induced by exposure of the shoot to light. Mol. Gen. Genet. 252:751-754.

Levine, A., Tenhaken, R., Dixon, R., and Lamb, C. 1994. $\mathrm{H}_{2} \mathrm{O}_{2}$ from the oxidative burst orchestrates the plant hypersensitive disease resistance response. Cell 79:583-593.

Lin, C-h., Yang S. L., and Chung, K-r. 2009. The YAP1 homolog-mediated oxidative stress tolerance is crucial for pathogenicity of the necrotrophic fungus Alternaria alternata in citrus. Mol. Plant-Microbe Interact. 22:942-952.

Morita, Y., Hyon, G., Hosogi, N., Miyata, N., Nakayashiki, H., Muranaka, Y., Inada, N., Park, P., and Ikeda, K. 2013. Appressorium-localized NADPH oxidase $\mathrm{B}$ is essential for aggressiveness and pathogenicity in the host-specific, toxin-producing fungus Alternaria alternata Japanese pear pathotype. Mol. Plant Pathol. 14:365-378.

Patel, T. K., Krasnyanski, S. F., Allen, G. C., Louws, F. J., Panthee, D. R., and Williamson, J. D. 2015. Tomato plants overexpressing a celery mannitol dehydrogenase (MTD) have decreased susceptibility to Botrytis cinerea. Am. J. Plant Sci. 6:1116-1125.

Smirnoff, N., and Cumbes, Q. J. 1989. Hydroxyl radical scavenging activity of compatible solutes. Phytochemistry 28:1057-1060.

Stoop, J. M. H., Williamson, J. D., Conkling, M. A., and Pharr, D. M. 1995. Purification of NAD-dependent mannitol dehydrogenase from celery suspension cultures. Plant Physiol. 108:1219-225.

Vélëz, H., Glassbrook, N., Daub, M. E. 2008. Mannitol biosynthesis is required for plant pathogenicity by Alternaria alternata. FEMS Microbiol. Lett. 285:122-129.

Williamson, J. D., Massel, M. O., Conkling, M. A., and Pharr, D. M. 1995. Sequence analysis of a mannitol dehydrogenase cDNA from plants reveals a function for the pathogenesis-related protein ELI3. Proc. Natl. Acad. Sci. U.S.A. 92:7148-7152.

Williamson, J. D., Desai, A., Krasnyanski, S. F., Ding, F., Guo, W-w., Nguyen, T-t., Olson, H. A., Dole, J. M., and Allen, G. C. 2013. Overexpression of mannitol dehydrogenase in zonal geranium confers increased resistance to the mannitol secreting fungal pathogen Botrytis cinerea. Plant Cell Tiss. Org. 115:367-375.

Yang, S. L., Lin, C-h., and Chung, K-r. 2009. Coordinate control of oxidative stress, vegetative growth and fungal pathogenicity via the AP1-mediated pathway in the rough lemon pathotype of Alternaria alternata. Physiol. Mol. Plant P. 74:100-110.

Yang, S. L., and Chung, K-r. 2012. The NADPH oxidase-mediated production of $\mathrm{H}_{2} \mathrm{O}_{2}$ and resistance to oxidative stress in the necrotrophic pathogen Alternaria alternata of citrus. Mol. Plant Pathol. 13:900-914. 